Volume 3 Issue 2 (2019) Pages 320 - 326

Jurnal Obsesi : Jurnal Pendidikan Anak Usia Dini

DOI: $10.31004 /$ obsesi.v3i2.176

\title{
Analisis Video Pembelajaran Share Book Reading Menggunakan Cerita Rakyat Sabai Nan Aluih pada Anak Usia Dini
}

\author{
Pitria Gusliati $^{1 凶}$, Delfi Eliza ${ }^{2}$, Sri Hartati ${ }^{3}$ \\ Pendidikan Anak Usia Dini, Universitas Negeri Padang
}

\begin{abstract}
Learning video media is a media that presents audio and visuals that contain learning messages. This research was conducted because of the importance of video game innovation in learning success. This study aims to determine the ability of students to make effective learning videos so as to support the achievement of learning objectives. This research is a descriptive study, which examines an object and searches for facts with the right interpretation. The object of analysis is the result of making a learning video using folklore, a simple story. Based on the results of the analysis, making video learning innovations by students is quite successful because students are able to produce media that are effective in their time allocation, easy to operate, and attractive in appearance. Although when the learning activities take place the class atmosphere is not conducive. And videos of learning activities are not from the beginning of the activity.
\end{abstract}

Keywords: folklore; sabai nan aluih; early childhood

\begin{abstract}
Abstrak
Media video pembelajaran merupakan media yang menyajikan audio dan visual yang berisi pesan-pesan pembelajaran. Penelitian ini dilakukan karena pentingnya peran sebuah video inovasi dalam keberhasilan pembelajaran. Penelitian ini bertujuan untuk mengetahui kemampuan mahasiswa dalam membuat video pembelajaran yang efektif sehingga mendukung ketercapaian tujuan pembelajaran. Penelitian ini merupakan penelitian deskriptif, yaitu meneliti sebuah objek dan pencarian fakta dengan interpretasi yang tepat. Objek analisis adalah hasil pembuatan video pembelajaran menggunakan cerita rakyat sabai nan aluih. Berdasarkan hasil analisis, pembuatan video inovasi pembelajaran oleh mahasiswa tergolong berhasil karena mahasiswa mampu menghasilkan media yang efektif dalam alokasi waktunya, mudah dalam pengoperasiannya, dan menarik dalam tampilannya. Walaupun saat kegiatan pembelajaran berlangsung suasana kelas kurang kondusif. Dan video kegiatan pembelajaran tidak dari awal kegiatan.
\end{abstract}

Kata kunci: cerita rakyat; sabai nan aluih; anak usia dini

Copyright (c) 2019 Pitria Gusliati, Delfi Eliza, Sri Hartati

$\triangle$ Corresponding author : Pitria Gusliati

Address : Padang, Sumatera Barat

Email : pitriagusliati07@gmail.com

ISSN 2356-1327 (Media Cetak)

ISSN 2549-8959 (Media Online) 


\section{PENDAHULUAN}

Media video pembelajaran biasanya berisi berisi pesan-pesan pembelajaran. Video sebagai media audio visual dan mempunyai unsur gerak akan mampu menarik perhatian dan motivasi anak dalam melaksanakan kegiatan pembelajaran. Menurut (Depdikbud, 1995) mengartikan video dengan: 1) bagian yang memancarkan gambar pada pesawat televisi; 2) rekaman gambar hidup untuk ditayangkan pada pesawat televisi. Video mampu merangkum banyak kejadian dalam waktu yang lama menjadi lebih singkat dan jelas dengan disertai gambar dan suara yang dapat diulang-ulang dalam proses penggunaannya.

Video mempunyai kekurangan dan kelebihan. menurut (Arsyad, Azhar Arsyad, \& Daryanto, 2011), beberapa kelebihan penggunaan media video, antara lain : 1) Video menambah suatu dimensi baru di dalam pembelajaran, video menyajikan gambar bergerak kepada siswa disamping suara yang menyertainya. 2) Video dapat menampilkan suatu fenomena yang sulit untuk dilihat secara nyata. Sedangkan kekurangannya, antara lain : 1) Opposition Pengambilan yang kurang tepat dapat menyebabkan timbulnya keraguan penonton dalam menafsirkan gambar yang dilihatnya. 2) Material pendukung Video membutuhkan alat proyeksi untuk dapat menampilkan gambar yang ada di dalamnya. 3) Budget Untuk membuat video membutuhkan biaya yang tidak sedikit.

Menurut (Cheppy, 2007) media video pembelajaran adalah media yang menyajikan audio dan visual yang berisi pesan-pesan pembelajaran baik yang berisi konsep, prinsip, prosedur, maupun teori aplikasi pengetahuan untuk membantu pemahaman terhadap suatu materi pembelajaran. Video merupakan bahan pembelajaran tampak dengar (audio visual) yang dapat digunakan untuk menyampaikan pesan-pesan/materi pelajaran. Dikatakan tampak dengar kerena unsur dengar (audio) dan unsur visual/video (tampak) dapat disajikan serentak.

Menurut (Sungkono, 2003), video yaitu bahan pembelajaran yang dikemas melalui pita video dan dapat dilihat melalui video/VCD player yang dihubungkan ke monitor televisi. Media video pembelajaran dapat digolongkan kedalam jenis media yang dapat dilihat dan didengar atau media audio visual aids (AVA). Biasanya media ini disimpan dalam bentuk pita atau piringan. (Arsyad et al., 2011) menyatakan media VCD adalah media dengan sistem penyimpanan dan perekam video dimana signal audio visual direkam pada disk plastic bukan pada pita magnetic.

Hasil penelitian yang dilakukan oleh (Fitria \& Juwita, 2018) menunjukkan bahwa video pembelajaran dapat diterapkan dalam membentuk karakter anak usia dini. video yang digunakan yaitu video blog (vlog), alasannya adalah anak umumnya gemar menonton.

Penelitian yang dilakukan oleh (Purwanto \& Rizki, 2015) menunjukkan bahwa video pembelajaran sangat layak digunakan. Video pembelajaran merupakan sumber belajar yang menarik dan memiliki banyak gambar serta dilengkapi visualisasi berupa video pembelajaran. Dalam hal ini beliau mengembangkan video pembelajaran matematika berbasis kontekstual.

Sementara itu, penelitian (Kholifah, 2016) menunjukkan bahwa pembelajaran menggunakan media video pembelajaran lebih baik daripada pengajaran konvensional. Dalam hal ini video pembelajaran yang digunakan berbasis swishmax dan perangkat lunak screencast o-matic melalui pendekatan kontekstual.

Berangkat dari beberapa hasil penelitian tersebut maka peneliti mencoba melakukan analisis terhadap video 
pembelajaran yang ada di youtube. Analisis video pembelajaran ini perlu dilakukan agar pembuat video bisa memberikan yang terbaik untuk kedepannya. Dalam hal ini, video yang akan dianalisis adalah video (Gusliati, 2018). Video ini di buat oleh peneliti sendiri. Tujuannya adalah supaya peneliti dapat menganalisis video tersebut baik dari segi materi yang disampaikan, kegiatan yang dilakukan, maupun dari tampilan video. Selain itu juga dalam rangka memupuk jiwa sportifitas dari peneliti sendiri untuk mampu menyebutkan kesalahan-kesalahan yang telah dilakukan dalam video tersebut, yang nantinya menjadi perbaikan buat peneliti.

Adapun judul video yang dianalisis adalah pembelajaran bercerita menggunakan cerita rakyat minangkabau. Pengertian cerita rakyat menurut (Kiefer, 2010) dalam kutipannya yaitu : "folktales have been defined as all forms of narrative, written or oral, which have come to be handed down through the years". Termasuk di dalamnya epik, balada, legenda, mitos dan fabel. Pengertian cerita rakyat menurut (Mustakim, 2005) yaitu cerita yang disampaikan secara lisan dari mulut ke mulut, dari generasi ke generasi lainnya yang tidak diketahui nama pengarangnya. (Kiefer, 2010) membuat beberapa ciri cerita rakyat yang dapat dibedakan dengan cerita lain yaitu struktur alur, karakter, tema, motif, dan jenis.

Struktur alur dalam cerita rakyat mengarah dan sederhana, terdiri atas pengulangan-pengulangan baik nayntian, puisi, dan tanggapan, waktu serta tempat dalam cerita tidak spesifik namun menceritakan sesuatu yang indah, pembukaan cerita biasanya menampilkan tempat, karakter dan konflik, kesimpulan cerita mengikuti klimaks yang sangat detail dan cepatl. Karakter cerita untuk anak lebih tegas menunjukkan kebaikan atau bahkan sebaliknya berprilaku kejam dan jahat.
Tema-tema yang sering diminati anak-anak berisi konflik dan diakhiri dengan penyelesaian yang indah.

Disamping itu model pembelajaran utamanya model pembelajaran sentra mempunyai peranan penting untuk membangun karakter anak melalui komunikasi positif, perancah, pembiasaan, dan konsistensi dalam membangun aturan. (Iswantiningtyas \& Wulansari, 2019)

Karakteristik cerita untuk anak yang telah disesuaikan untuk anak Indonesia oleh (Musfiroh, 2008) dijelaskan dalam tujuh karakeristik. Karakteristik tersebut yaitu tema, amanat, plot, tokoh dan penokohan, sudut pandang, latar, dan sarana kebahasaan. Tema untuk anak TK sebaiknya bertema sosial maupun ketuhanan, bersifat tradisional (bertentangan baik dan buruk, kebenaran dan kejahatan). Amanat dapat diartikan sebagai pesan moral. Untuk anak usia dini amanat harus ada baik implisit maupun eksplisit. Guru berperan dalam memilih cerita yang mengandung amanat kepada anak. Hal ini memengaruhi ketertarikan anak terhadap cerita.

Guru sebaiknya mampu memilih cerita yang tepat sesuai usia anak. Plot atau alur dalam cerita untuk anak usia dini harus sederhana dan berurut. Anak akan kesulitan jika alur ceritanya maju mundur. Waktu pada video pembelajaran juga perlu diperhatikan mengingat rentang perhatian anak yang cukup pendek. Sudut pandang dipilih yang memudahkan anak untuk mengidentifikasi, menginterpretasi, dan memahami cerita dengan bantuan pencerita yang menyampaikan tentang tokoh, peristiwa, tindakan, dan motivasi dari cerita tersebut. Latar cerita untuk anak harus sesuai dengan perkembangan kognitif dan moral anak, latar yang tepat dapat digunakan besok dan sekarang, menghindari rincian waktu agar anak tidak 
terbebani mengingat detail waktu tersebut, dan tidak dijelaskan secara detail.

Setelah semua kritteria tersebut terpenuhi, maka seorang anak diharapkan mampu bercerita menggunakan buku cerita. Ketika seorang anak menceritakan buku cerita yang sudah dikenalnya sambil melihat gambar dalam buku cerita anak sudah memiliki kemampuan dalam bercerita. Keaksaraan sebagai hasil dari keterlibatan anak dalam melek literasi. Literasi adalah gabungan antara sosial interaksi yang mengikuti kegiatan yang membuat ini sangat penting untuk perkembangan anak. Keaksaraan tidak hanya mengajarkan anak fungsi sosial tetapi keaksaraan juga menghubungkan keasyikan dan kepuasan sehingga dapat meningkatkan keinginan anak untuk terlibat dalam kegiatan literasi.

Kesiapan literasi bukanlah periode di mana seorang anak bergerak dari perilaku belum mengenal literasi ke literasi awal. Kesiapan untuk anak-anak dianggap sebagai periode transisi. Beberapa ahli berpendapat bahwa seperangkat gagasan tentang bagaimana anak-anak belajar tentang membaca, menulis, dan memahami bahasa tertulis didasarkan pada teori, penelitian, dan praktik.

Namun keaksaraan awal sebagai waktu kesiapan membaca awal adalah dasar untuk menumbuhkan kesadaran bahwa menulis memiliki arti. Buku-buku bergambar tanpa kata menggambarkan hampir tidak ada kata dan ilustrasi atau gambar yang memberi makna dan fungsi naratif. Berbeda halnya dengan buku teks saat membaca buku teks tanpa teks (buku bergambar tanpa kata) pembaca membuat arti dari ilustrasi gambar. Buku bergambar adalah cara terbaik dan positif dalam akuisisi literasi sesuai dengan kualitas buku. Interaksi anak-anak dengan buku cerita adalah cara yang efektif untuk pengembangan literasi dengan mengintegrasikan literatur ke dalam kurikulum. Buku dengan buku bergambar tanpa kata juga bisa digunakan untuk tujuan pedagogik termasuk literasi yang muncul, kedua bahasa, pembelajaran, penulisan kreatif dan komprehensif bacaan.

Cerita rakyat Sabai Nan Aluih adalah salah satu rakyat yang terdapat di Minangkabau Sumatera Barat. Cerita ini mengisahkan tentang seorang anak yang sangat cantik dan sopan santun serta halus budi bahasanya bernama Sabai Nan Aluih. Ibunya mengajarkan semua kebaikan kepada Sabai. Mulai dari memasak, cara bergaul, dan juga beberapa keterampilan dalam kehidupan. Sabai anan aluih memiliki sorang adik yang bernama mangkutak alam. Mangkutak sangat disayang oleh ayahnya. Semua keinginnya harus dipenuhi. Selain itu, ayah Sabai nan aluih suka berlatih ilmu beladiri. Suatu hari ia bertanding dengan temannya yang membuat ayah si Sabai terluka. Sabai sangat sedih melihat kejadian tersebut. Tetapi lain halnya dengan Mangkutak yang tidak memiliki rasa simpati. Mangkutak tidak mau memperdulikan ayahnya yang kesakitan.

Pesan-pesan yang dapat diangkat dari cerita rakyat Sabai Nan Aluih adalah seorang anak harus memiliki keterampilan dalam hidupnya, harus mampu bergaul dimasyarakat, tidak semua keinginan anak harus dipenuhi, kita harus memiliki rasa empati dan memupuk kepedulian.

Dalam cerita tersebut aspek yang dapat dikembangkan pada anak saat pembelajaran adalah aspek nilai agama moral, anak diajarkan bagaimana berperilaku dilingkungannya, memiliki sopan santun dalam bermasyarakat. Aspek sosial emosional, diajarkan ketika anak mampu menahan egonya. Sehingga tidak semua keinginannya harus dipenuhi oleh orangtua. Aspek kognitif, anak diharapkan memahami tentang nilai budaya yang 
324 | Analisis Video Pembelajaran Share Book Reading Menggunakan Cerita Rakyat

terdapat dalam cerita rakyat Sabai nan aluih. Aspek fisik, dapat diajarkan ketika anak diminta untuk mempraktekan latihan beladiri sesuai usia anak. Aspek bahasa, anak mampu menceritakan kembali cerita rakyat sabai nan aluih. Aspek seni, dapat diajarkan melalui keterampilan hidup yang perlu dimiliki anak, misalnya menyulam, menenun, dan sebagainya.

\section{METODOLOGI}

Penelitian menggunakan metode deskriptif kualitatif. Analisis data menggunakan langkah-langkah yang dikemukakan oleh Miles dan Huberman dalam (Sugiyono, 2011) yaitu pengumpulan data (data collection), reduksi data (data reduction), display data (data display), verifikasi dan penegasan kesimpulan (conclution drawing and verivication).

\section{HASIL DAN PEMBAHASAN}

Video yang di analisis menggunakan video (Gusliati, 2018). strategi pembelajaran yang diterapkan adalah share book reading menggunakan cerita rakyat sabai nan aluih. Video menampilkan kegiatan guru bercerita menggunakan cerita tradisional minangkabau.

Menurut (Eliza, 2017) cerita tradisional Minangkabau bagi anak TK merupakan cara untuk mengenalkan kepada anak budaya serta nilai-nilai yang terdapat di dalamnya. Membacakan cerita yang berulang- ulang akan mempengaruhi anak secara sadar ataupun tidak, anak akan menyerap nilai-nilai tersebut. Bercerita merupakan alat untuk mengajarkan anak sosial dan nilai-nilai moral. Dalam sejarahnya bercerita telah digunakan untuk mendidik yang sifatnya menghibur bagi anak-anak.

\section{Kesesuaian materi dengan tema tentang inovasi pembelajaran}

Hasil penelitian menunjukan bahwa materi yang digunakan dalam share book reading sesuai untuk anak usia dini. Cerita rakyat sabai nan aluih banyak memberikan pesan moral kepada anak. Menurut peneliti tema tentang cerita rakyat merupakan bentuk dari inovasi pembelajaran. Karena guru jarang menggunakan cerita rakyat dalam bercerita pada anak usia dini. Guru lebih sering menggunakan cerita seperti cerita putri salju, cerita fabel, dan cerita dari luar negeri yang sudah diterjemahkan. Sehingga anak tidak lagi kenal dengan cerita rakyat yang ada di daerahnya. Untuk itu, video ini menjadi suatu inovasi dalam pelaksanaan pembelajaran anak usia dini. Selain itu juga dapat melestarikan cerita rakyat yang ada di Minangkabau.

\section{Kegiatan pembukaan}

Berdasarkan hasil observasi peneliti, kegiatan pembukaan dalam video yang ditampilkan dimulai dengan sepatah kata dari guru tentang pentingnya cerita rakyat bagi anak usia dini. Guru tidak menampilkan kegiatan pembukaan pada saat kegiatan pembelajaran berlangsung. Padahal kegiatan pembukaan pada saat kegiatan pembelajaran sangat diperlukan dalam video ini. Agar penonton menerima infromasi dari video secara menyeluruh.

\section{Kegiatan bercerita}

Hasil observasi menunjukan bahwa guru bercerita menggunakan buku cerita rakyat sabai nan aluih. Saat guru bercerita anak fokus mendengarkan. Tetapi suasana kelas sangat berisik sehingga tidak terlihat kenyamanan saat pembelajaran berlangsung. Suara guru dalam menyampaikan cerita sangat jelas dan dapat diikuti oleh anak. Buku cerita yang digunakan guru hendaknya memiliki gambar yang full color. Melalui bercerita 
anak memperoleh gambaran peristiwa yang terdapat di dalam cerita Minangkabau. Hal ini merupakan jembatan bagi anak untuk memahami kehidupan sosial masyarakat Minangkabau dengan nilai-nilai yang terdapat dalam cerita (Eliza, 2017). Membacakan cerita kepada anak kemudian dilakukan tanya jawab mengenai cerita yang dibacakan hal ini cara untuk merangsang anak agar dapat mengapresiasi cerita. Adanya dialog serta interaksi antara guru dan anak dapat mengembangkan fungsi bahasa, kognitif, personality atau kepribadian, dan tingkah laku sosial. Sedangkan peneliti yang lain, seperti Howard Gardner dan Brian Sutton, Smith, melakukan eksplorasi terhadap perasaan anak terhadap cerita, dongeng, (sense of story, fairy and tales). Hal ini dapat memperbaiki afektif anak. Melalui cerita sabai nan aluih dapat memberikan makna yang lebih dalam kepada element dalam cerita tersebut.

Guru melakukan recalling pada anak dengan bertanya tentang tokoh yang ada dalam cerita. Semua anak ikut terlibat dalam menjawab pertanyaan guru. Anak terlihat memiliki daya ingat yang kuat. Anak juga mampu menyebutkan jumlah tokoh yang ada dalam cerita. Sayangnya guru tidak bertanya lebih mendalam tentang cerita rakyat sabai nan aluih yang telah didengar oleh anak. seperti pertanyaan tentang karakter tokoh. Karakter siapa yang patut ditiru, dan sebagainya.

Pengembangan karakter anak dapat dimulai dengan mengembangkan pengetahuan moral anak, mengembangan perasaan moral, dan melakukan tindakan moral. (Lickona, 2004) menyatakan bahwa pengembangan karakter bagi anak adalah penanaman nilai-nilai, moral sebagai agent moral yang meliputi tiga komponen: (1) pengetahuan moral (knowing), (2) sikap moral (affect), (3) tindakan moral (action).

\section{Kegiatan drama}

Hasil pengamatan peneliti melihat adanya cuplikan tampilan kegiatan drama yang dilakukan oleh anak usia dini. Anak terlihat memainkan peran sesuai dengan karakter yang ada dalam cerita. Sayangnya kegiatan drama yang ditampilkan tidak dimulai dari awal cerita atau terpenggalpenggal. Sehingga cerita yang diperankan tidak runtut. Jika penonton hanya melihat kegiatan drama yang diperankan anak tanpa memahami cerita rakyat yang diperankan akan membuat penotnon kesulitan dalam memahami cerita tersebut. Selain itu, persiapan drama juga kurang matang. Hal ini terlihat dari kegiatan tidak menggunakan panggung dan perlengkapan yang digunakan seadanya. Namun, dalam pelaksanaan drama anak mampu memerankan tokoh yang ada dalam cerita. Diakhir video dipaparkan pesan moral yang terkandung dalam cerita rakyat sabai nan aluih. Tokoh pemeran dalam drama sabai nan aluih juga ditampilkan. Begitu juga dengan tim yang terlibat dalam pembuatan video tersebut. Sayangnya, lagu pengiring yang digunakan diakhir video tidak sesuai dengan tema pembelajaran yaitu tentang cerita rakyat daerah minangkabau. Seharusnya guru menggunakan lagu daerah minangkabau sebagai pengiringnya.

\section{KESIMPULAN}

Video yang dianalisis merupakan contoh inovasi pembelajaran karena menggunakan cerita rakyat daerah minangkabau. Video memaparkan tentang guru bercerita menggunakan cerita rakyat sabai nan aluih dan anak memerankan kegiatan drama berdasarkan cerita sabai nan aluih yang telah diceritakan oleh guru. Sayangnya video yang di paparkan kurang lengkap. Dalam hal ini kegiatan pembelajarannya tidak mencerminakan kegiatan yang runtut dari awal hingga akhir 
326 | Analisis Video Pembelajaran Share Book Reading Menggunakan Cerita Rakyat

kegiatan. Begitu juga dengan drama yang ditampilkan oleh anak. walaupun demikian, anak mampu memerankan drama sesuai dengan cerita rakyat sabai nan aluih.

\section{UCAPAN TERIMA KASIH}

Terimakasih kepada dosen pembimbing, Ibu Dr. Delvi Eliza, M.Pd dan Ibu Dra. Sri Hartati, M.Pd yang telah membantu dan memfasilitasi proses pelaksanaan penelitian serta Tim Editor Jurnal Obsesi yang sudah memberikan kesempatan sehingga jurnal ini siap untuk di terbitkan.

\section{DAFTAR PUSTAKA}

Arsyad, A., Azhar Arsyad, \& Daryanto. (2011). Media Pembelajaran. Jakarta: Raja Grafindo Persada.

Cheppy, R. (2007). Pedoman Pengembangan Media Video. Jakarta: P3AI UPI.

Depdikbud. (1995). Kamus Besar Bahasa Indonesia. Jakarta: Balai Pustaka.

Eliza, D. (2017). Pengembangan Model Pembelajaran Karakter Berbasis Cerita Tradisional Minangkabau untuk Anak Usia Dini. Pedagogi, 3. https://doi.org/http://dx.doi.org/10.306 51/pegi.v3i3b.1072

Fitria, Y., \& Juwita, J. (2018). Utilization of Video Blogs (Vlogs) in Character Learning in Early Childhood. Jurnal Obsesi : Jurnal Pendidikan Anak Usia Dini, 2(2), 211. https://doi.org/10.31004/obsesi.v2i2.8 7

Gusliati, P. (2018). sabai nan aluihpembelajaran bercerita menggunakan cerita rakyat minangkabau.

Iswantiningtyas, V., \& Wulansari, W. (2019). Penanaman Pendidikan Karakter pada Model Pembelajaran BCCT (Beyond Centers and Circle Time). Jurnal Obsesi: Jurnal
Pendidikan Anak Usia Dini, 3(1), 110. https://doi.org/10.31004/obsesi.v3i1.1 06

Kholifah, S. (2016). The Development of Learning Video Media Based on Swishmax and Screencast O-Matic Softwares through Contextual Approach. Dinamika Pendidikan. https://doi.org/10.15294/dp.v11i1.870 1

Kiefer, B. Z. (2010). Charlotte Huck's Children's Literature. New York: The McGrawHillCompanies.

Lickona, T. (2004). Character matters. New York: Touchstone.

Musfiroh, T. (2008). Cerdas Melalui Bermain. Jakarta: PT Grasindo.

Mustakim, M. N. (2005). Peranan cerita dalam pembentukan perkembangan anak TK. Jakarta: Depdiknas.

Purwanto, Y., \& Rizki, S. (2015). Pengembangan Bahan Ajar Berbasis Kontekstual Pada Materi Himpunan Berbantu Video Pembelajaran. AKSIOMA Journal of Mathematics Education, 4(1), 67-77. https://doi.org/10.24127/ajpm.v4i1.95

Sugiyono. (2011). Metode Penelitian Kuantitatif, Kualitatif, dan $R \& D$. Bandung: Alfabeta.

Sungkono. (2003). pengembangan dan pemanfaatan bahan ajar modul dalam proses pembelajaran. Yogyakarta. 